- 研究报告・

\title{
尖峰岭热带山地雨林根部真菌-植物 互作网络结构特征
}

\author{
杨思琪 ${ }^{1}$ 张 琪 ${ }^{1}$ 宋希强 ${ }^{1}$ 王 健 $^{1}$ \\ 李意德 ${ }^{2}$ 许 涵 $^{2}$ 郭守玉 $^{3}$ 丁 琼 ${ }^{*}$ \\ 1 (海南大学热带农林学院环南海陆域生物多样性研究中心, 海口 570228) \\ 2 (中国林业科学研究院热带林业研究所, 广州 510520) \\ 3 (中国科学院微生物研究所真菌学国家重点实验室, 北京 100101)
}

摘要: 不同功能群的根部真菌可能会与植物差异性地互作, 并进一步影响地下真菌与植物群落构建。本研究采用 Illumina Miseq测序方法检测了海南尖峰岭热带山地雨林中常见植物的根部真菌; 采用网络分析法比较了从枝菌 根(AM)真菌、外生菌根(ECM)真菌, 以及所有根部真菌与植物互作的二分网络(bipartite networks)结构特性。从械 树科、番荔枝科、夹竹桃科、冬青科、棕榈科、壳斗科、樟科和木犀科等 8 科植物的根系中, 检测到 297,831 条真 菌ITS1序列, 这些序列被划为 1,279 个真菌分类单元(OTUs), 其中子囊菌门748个、担子菌门 354 个、球囊菌亚门 80 个, 以及未知真菌97个。核心根部真菌群落(420个OTUs)中, 至少有三类不同生态功能的真菌常见, 即丛枝菌根真 菌(40个OTUs, 占总序列数 $23.4 \%$ )、外生菌根真菌(48个OTUs, 13.9\%)和腐生型真菌(83个OTUs, $19.8 \%)$ 。尖峰岭山 地雨林根部真菌-植物互作网络结构特性的指标普遍显著高于/低于假定物种随机互作的零模型期待值。在群落水 平, 不同功能型的根部真菌-植物互作网络表现出不同或相反的结构特性, 如丛枝菌根互作网络表现为比零模型 预测值高的嵌套性和连接性, 以及比零模型低的专一性, 而外生菌根互作网络呈现出比零模型预测值低的嵌套性 和连接性, 以及比零模型高的专一性。在功能群水平, 植物的生态位重叠度在AM互作网络高, 而ECM互作网络低; 真菌的生态位宽度在ECM互作网络窄, 而在AM互作网络较宽。共现(Co-occurrence)网络分析进一步揭示, ECM群 落的物种对资源的高度种间竞争(植物、真菌高C-score), 以及AM群落的物种无明显种间竞争(低C-score), 可能分 别是形成反嵌套ECM互作网络及高嵌套AM互作网络结构的原因。上述结果说明, 尖峰岭山地雨林中至少有两种 及以上的种间互作机制调节群落构建: 驱动AM互作网络咒余(nestedness)及ECM互作网络的高生态位分化(专一 性)。本研究在同一个森林内探讨了不同功能型的真菌-植物互作特性, 对深入理解热带森林的物种共存机制和生 态恢复具有重要意义。

关键词：根部真菌；热带山地雨林；互作网络；嵌套性；专一性

\section{Structural features of root-associated fungus-plant interaction networks in the tropical montane rain forest of Jianfengling, China}

Siqi Yang ${ }^{1}$, Qi Zhang ${ }^{1}$, Xiqiang Song ${ }^{1}$, Jian Wang ${ }^{1}$, Yide $\mathrm{Li}^{2}$, Han $\mathrm{Xu}^{2}$, Shouyu Guo ${ }^{3}$, Qiong Ding ${ }^{1 *}$

1 Research Center for Terrestrial Biodiversity of the South China Sea, Institute of Tropical Agriculture and Forestry, Hainan University, Haikou 570228

2 Research Institute of Tropical Forestry, Chinese Academy of Forestry, Guangzhou 510520

3 State Key Laboratory of Mycology, Institute of Microbiology, Chinese Academy of Sciences, Beijing 100101

Abstract: Functionally diverse root-associated fungi may differentially interact with host plants, potentially affecting the assembly processes of belowground plant and fungi communities. Here, we applied the Illumina Miseq sequencing technique to identify root-associated fungi of plants which were co-dominant in a tropical montane rain forest on Hainan Island, China. Structural features of bipartite networks were compared among

收稿日期: 2018-12-25; 接受日期: 2019-02-27

基金项目: 国家自然科学基金(31360107; 31670628)和中国林业科学研究院中央级公益性科研院所基本科研业务费专项资金(CAFYBB2017ZE01)

* 通讯作者 Author for correspondence. E-mail: dingqiong@hainu.edu.cn 
the whole root-associated, arbuscular mycorrhizal (AM) and ectomycorrhizal (ECM) fungus-plant interactions. A total of 297,831 fungal ITS1 sequences were obtained from eight families including Aceraceae, Annonaceae, Apocynaceae, Aquifoliaceae, Arecaceae, Fagaceae, Lauraceae, and Oleaceae. Fungal sequences were assigned to 1,279 OTUs comprised of Ascomycota (748 OTUs), Basidiomycota (354), Glomeromycota (80), and unidentified fungi (97). At least three functional groups of fungi i.e. putatively ECM (40 OTUs, represented $23.4 \%$ of the total fungal reads), AM (40,13.9\%) and saprophyte (83, 19.8\%) were prevalent in the core root-associated fungal community (420 OTUs) of the tropical montane rain forest. Network analysis indicated that AM, ECM and root-associated fungus-plant interaction network showed structural features which cannot be predicate by null models assuming species interact randomly. Community level indices behaved differently among different ecotypes of fungus-plant interactions. Specifically, the degree of nestedness (NODF) and connectance were higher, while specialization was lower in the AM interaction network than the expected values from null models. In contrast, the ECM interaction network had a significantly higher degree of specialization and lower nestedness and connectance than the null models. At guild levels, plant niche overlap of AM and ECM interactions are higher and lower than the null model, respectively. Niche breadth of ECM fungi was narrower than that of AM fungi. Co-occurrence patterns of plant and fungus further confirmed competition for resources was intense in ECM interaction network (high C-score of both plants and fungi) and weak in the AM interaction network (low C-score). These findings suggest that at least two modes of interspecific interactions are critical for the assembly and coexistence of root-associated fungal communities, i.e. redundancy (nestedness) of AM interactions, and niche differentiation (specialization) of ECM interactions. Here we provide a comprehensive exploration of the interactions among functionally diverse root-associated fungal guild within a forest, which is key to understand the mechanisms maintaining species coexistence in tropical forests.

Key words: root-associated fungi; tropical montane rain forest; interaction network; nestedness; specialization

根部真菌(root-associated fungi, RAF)通常指生 长于植物根系内部、根系表面, 以及受根系分泌物 影响的根际范围内的真菌的总称(Toju et al, 2013a)。 RAF群落中, 不同谱系与生态功能的真菌共存, 并 形成复杂的互作网络, 对陆地生态系统的养分循环 及植物群落动态等过程有重要调节作用(Toju et al, 2013a; Almario et al, 2017), 如菌根型真菌促进植物 吸收养分(Toju et al, 2013a; Cardoso et al, 2017), 腐 生型真菌参与复杂有机质的分解(Cannon \& Kirk, 2007; Almario et al, 2017), 病原型真菌通过调节幼 苗死亡率而影响植物种群动态(Merges et al, 2018)。 这些不同生态类型的真菌之间可能存在竞争或有 益的互作, 对生物群落的构建有重要意义。

随着测序技术的进步, 微生物群落的种间互作 特性研究不再限于少量物种而逐渐转向复杂群落 (complex communities)。网络分析法在研究高度复 杂的群落特性方面优于一般的群落分析法(James et $\mathrm{al}, 2012)$, 它能在群落、功能群、个体多个层面上分 析生物的种间互作特性(Bascompte, 2007), 借助网 络分析法, 结合零模型比较, 可以推断生物群落的 非随机性构建规律(Ulrich \& Gotelli, 2007)。通过结 合群落多元统计分析法, 还可以揭示中性过程、生
态与进化如何驱动生物群落构建(Tylianakis, 2009; Vázquez et al, 2009; Chen et al, 2017)。近期的生物种 间互作网络研究发现, 生物网络普遍具有一些有利 于群落稳定性的结构, 如嵌套性(nestedness)、专一 性(specialization)等(Bascompte et al, 2003; Fortuna et al, 2010; Thebault \& Fontaine, 2010; Burkle et al, 2013)。嵌套性是指在生物互作的二分网络(bipartite network)中, 双方的偶见种倾向于跟对方的常见种 互作, 相比之下, 常见种却能同时与对方的常见种 和偶见种互作, 从而形成一种类似于俄罗斯套娃的 嵌套结构(Bascompte et al, 2003)。嵌套性的生物互 作网络具有较高的呪余性, 生物群落整体上更能适 应环境干扰, 有较高的稳定性和持久性(Bascompte et al, 2003; Burkle et al, 2013)。嵌套性的结构可降低 种间竞争, 促进多物种共存(Bastolla et al, 2009), 在 传粉网络、种子传播网络、食物网中较普遍。专一 性是指二分互作网络中, 双方的物种对彼此的互作 对象在整体上呈现明显的选择性或偏好性。高专一 性意味着高度的生态位分化, 是物种共存的重要机 制之一(Blüthgen et al, 2008)。物种共现(co-occurrence)格局是推断有机体之间潜在的种间互作关系, 如竞争(competition)或互利(facilitation)的有效方法 
之一, 也有助于揭示生物群落构建规律 (Gotelli \& McCabe, 2002)。

当前有限的根部真菌-植物互作网络结构特性 研究中, 网络分析法主要应用于单一功能型的真菌 与植物的互作网络, 如丛枝菌根型 (arbuscular mycorrhizal, AM) (Chagnon et al, 2012; Chen et al, 2017; Gao et al, 2019)、外生菌根型(ectomycorrhizal, ECM) (Bahram et al, 2014)、致病型互作网络(Merges et al, 2018)。然而, 这些研究忽视了一个事实, 即 RAF群落中可能同时共存多种营养型的真菌, 如壳 斗科与松科植物除了被 ECM真菌侵染以外，还同时 被AM真菌(Dickie et al, 2001)、根部内生真菌侵染 (Newsham, 2011; Toju et al, 2013b; Yamamoto et al, 2014)。单一功能型的真菌-植物互作网络必将忽视 共存的不同功能型真菌之间的潜在互作, 如日本温 带次生林的柇幼苗RAF群落中，一些成对的菌根真 菌与内生真菌的空间格局呈聚集分布, 说明不同功 能型的真菌间可能存在竞争、偏利或互惠的互作特 性(Yamamoto et al, 2014)。因此, 全面揭示根部真菌 -植物互作网络, 以及不同功能型(AM、ECM)真菌植物的互作亚网络的结构特性, 并且在同一研究地 点比较不同互作网络的结构差异, 将有助于揭示地 下真菌群落的构建规律, 从而促进对土壤生态系统 的管理。

本研究以海南尖峰岭地区的热带雨林固定样 地(60 ha)为平台, 广泛地采集样地中常见植物的根 系, 以高通量测序平台Miseq对真菌的核糖体内转 录间隔区(ITS)序列进行测序, 以揭示热带山地雨林 RAF的多样性。在此基础上, 回答如下问题: (1)海南 岛热带山地雨林的根部真菌-植物互作网络是否具 有生物互作网络的一般特性, 如显著高于零模型的 嵌套值? (2)不同功能型(如AM、ECM)真菌-植物的 种间互作网络结构是否具有差异?

\section{材料与方法}

\section{1 研究地点}

海南尖峰岭国家级自然保护区位于海南岛西 南部, 地跨乐东、东方两县市, 地理坐标为 $108^{\circ} 44^{\prime}-$ $109^{\circ} 02^{\prime} \mathrm{E}, 18^{\circ} 23^{\prime}-18^{\circ} 52^{\prime} \mathrm{N}$, 总面积 $20,170 \mathrm{ha}$ 。保护 区内最高峰海拔 $1,412 \mathrm{~m}$ 。属热带岛屿季风气候, 干 湿两季明显, 5-10月为雨季, 11月至翌年4月为旱季, 年降水量1,000-3,600 mm, 年平均气温 $24.5^{\circ} \mathrm{C}$, 最
冷和最温暖的月平均气温分别为 $19.4^{\circ} \mathrm{C}$ 和 $27.3^{\circ} \mathrm{C}$ 。 土壤类型多样，最常见的是山地红壤或红壤，海拔 较高的山顶区域是山地淋溶表潜黄壤(蒋有绪和卢 俊培，1991)。保护区内森林植被类型丰富，植被垂 直分布带谱明显，由低至高依次为热带半落叶季雨 林、热带常绿季雨林、热带山地雨林、山顶苔藓矮 林4个类型。其中, 海拔650-1,100 m范围内的热带 山地雨林分布最广, 面积最大, 种类丰富, 常见的 有樟科、壳斗科、棕榈科、冬青科、夹竹桃科, 为 热带植物区系的主要科(许涵等, 2015)。

\section{2 采样方法与样品前处理}

样品采自中国林业科学研究院尖峰岭森林生 物多样性动态监测大样地。大样地位于尖峰岭热带 山地雨林区内的五分区原始林内，海拔 866$1,016 \mathrm{~m}$ ，总面积60 ha，植株密度达7,328株/ha。首 先将大样地沿长轴划分为两个 $1,000 \mathrm{~m} \times 300 \mathrm{~m}$ 的子 样地，将南侧子样地划分成30个 $100 \mathrm{~m} \times 100 \mathrm{~m}$ 网格， 从中随机抽取 5 个网格用于根系采集。在这 5 个网格 中，每个随机设置1个 $40 \mathrm{~m} \times 40 \mathrm{~m}$ 的样方，再将每 个样方进一步分为 64 个子样方, 并在每个子样方内 随机设置 1 个 $0.5 \mathrm{~m} \times 1 \mathrm{~m}$ 的矩形采样框。先去除矩形 采样框内地表的调落物层, 用铁铲沿矩形框外围切 断根系, 然后将框内表层 $20 \mathrm{~cm}$ 以上的土壤翻转, 轻缓地摇动土层使其松散, 从而使根与粘附的土壤 分离，挑取 $4-5$ 段分枝最多、最长的根段，置于塑料 封口袋中, 当天带回实验室暂存于 $-20^{\circ} \mathrm{C}$ 冰箱中。提 取根系总DNA前，将根系在盆中浸泡 $1 \mathrm{~h}$, 然后在自 来水下强力冲洗, 以去除根表附着的土壤颗粒及杂 质，确保附着于根表面的其他植物细根完全去除。 摘取每个根段上的所有一级侧根, 用去离子水清洗3 遍，转移至离心管中，于 $-80^{\circ} \mathrm{C}$ 下保存。

\section{3 分子检测}

\subsubsection{DNA提取与植物鉴定}

从前期保存的每份根系样品中取出1-3个根尖, 用去离子水冲洗两遍, 转移到 $2 \mathrm{~mL}$ 离心管, 加入50 $\mu \mathrm{L}$ 的 CTAB缓冲液以及 2 粒直径为 $5 \mathrm{~mm}$ 的钢珠, 放 于 $-40^{\circ} \mathrm{C}$ 冰箱中预冷冻 $2 \mathrm{~h}$, 将冷冻的样品放于高通 量组织研磨仪(TS48), 于50 Hz振荡35 s, 使组织呈 匀浆状。加入 $650 \mu \mathrm{L} \mathrm{CTAB}$ 缓冲液, 参考黄彩微等 (2017) 的方法提取根系总DNA。采用引物 $p s b A 3$ (5'-GTTATGCATGAACGTAATGCTC-3') 和 $t r n \mathrm{H}$ (5'-CGCGCATGGTGGATTCACAATCC-3') 扩 增植 
物叶绿体trnH-psbA片段, 用以鉴定每份根系样品 的植物身份。PCR扩增反应体系为 $25 \mu \mathrm{L}$, 含 $0.5 \mathrm{U}$ Taq聚合酶(Aidlab, 北京), $2.5 \mu \mathrm{L} 10 \times$ PCR 缓冲液, $2 \mu \mathrm{L}(2.5 \mathrm{mM}) \mathrm{dNTPs}, \operatorname{trnH}$ 与 $p s b \mathrm{~A} 3$ 引物 $(10 \mu \mathrm{M})$ 、 $5 \%$ BSA和DNA (10-100 ng/uL) 各 $1 \mu \mathrm{L}$ 。PCR反应程 序为: 在 $95^{\circ} \mathrm{C}$ 变性 $5 \mathrm{~min}$, 然后进行 30 个循环: $95^{\circ} \mathrm{C}$ $30 \mathrm{~s}, 60^{\circ} \mathrm{C} 30 \mathrm{~s}$ 和 $72^{\circ} \mathrm{C} 2 \mathrm{~min}$, 最后在 $72^{\circ} \mathrm{C}$ 延伸 10 $\mathrm{min}$ 。将trnH-psbA序列鉴定为相同科的植物对应的 所有DNA样品各取 $1 \mu \mathrm{L}$ 混合, 委托北京奥维森生物 技术公司在 Miseq 平台下采用引物 ITS1F (5'-CTTGGTCATTTAGAGGAAGTAA-3') 和 ITS2 (5'-TGCGTTCTTCATCGATGC-3') 对真菌的ITS1区 进行测序。PCR扩增反应体系为 $25 \mu \mathrm{L}$, 含有 $30 \mathrm{ng}$ DNA样品, $3 \mu \mathrm{L}$ BSA (2 ng/uL), 12.5 uL $2 \times$ Taq Plus Master Mix, ITS1F 与 ITS2 引物 $(5 \mu \mathrm{M})$ 各 $1 \mu \mathrm{L}$, 加 $\mathrm{ddH}_{2} \mathrm{O}$ 至 $25 \mu \mathrm{L}$ 。PCR反应程序为: 在 $94^{\circ} \mathrm{C}$ 变性 $5 \mathrm{~min}$, 然后进行 32 个循环: $94^{\circ} \mathrm{C} 30 \mathrm{~s}, 55^{\circ} \mathrm{C} 30 \mathrm{~s}$ 和 $72^{\circ} \mathrm{C} 1$ $\min$, 最后在 $72^{\circ} \mathrm{C}$ 延伸7 min。

\subsection{2 序列合并与分析}

首先，根据序列首尾两端的barcode和引物区 分样品, 使其调整为 $5^{\prime}-3^{\prime}$ 方向, 过滤原始序列中尾 部质量20以下的碱基, 设置50 bp的窗口, 如果窗口 内的平均质量值低于 20 , 从窗口开始截去后端碱基, 过滤50 bp以下的read; 然后, 用PEAR软件(Zhang et al, 2013)将成对reads拼接成一条序列, 最小 overlap 长度为 $10 \mathrm{bp}$, 且 overlap区允许的最大错配比率为 0.1。使用USEARCH软件(Edgar, 2010)进行序列分析, 先用UPARSE算法对质控后的序列进行聚类, 相似 性 $\geq 97 \%$ 的不同序列被划分为同一分类单元 (operational taxonomic units, OTU) (Edgar, 2013); 再以UNITE真菌数据库(Kõljalg et al, 2013)为参考 数据库, 用UCHIME算法剔除嵌合体序列; 接着将 OTU的代表序列在UNITE真菌数据库中检索, 根据 近缘序列的谱系信息来推断代表序列的谱系地位 (Edgar, 2018), 最终创建OTUs表。在后续所有分析 中, 除球囊菌亚门采用93\%阈值(Thiéry et al, 2016) 外，其他真菌用97\%阈值(Smith \& Peay, 2014)。对于 有明确谱系信息的真菌OTUs, 用FUNGuild软件 (Nguyen et al, 2016)注解其生态功能, 如ECM真菌、 $\mathrm{AM}$ 真菌、兰科植物菌根真菌、杜鹃花菌根真菌、内 生真菌、病原真菌、腐生真菌(Tedersoo et al, 2014)。 约 $46.4 \%$ 的真菌OTUs (61.3\% reads)的功能可以被解
析。高通量测序结果上传至GenBank数据库, BioSample登录号为SAMN10448655-SAMN10448662。

\section{4 数据分析}

因为不同科植物检测到的真菌序列数有差异 (31,589-50,791), 首先采用稀释法将每科植物的 RAF的reads数稀释到 31,580 reads。用基于reads的物 种累积曲线评估本研究中得到的RAF群落物种是 否能够较为全面地反映热带山地雨林的RAF物种 库, 以及真菌-植物相互作用数的取样是否全面。其 次，根据序列划分的OTUs和FUNGuild软件对真菌 生态功能注解的结果，建立植物为行、真菌为列的 相互作用矩阵, 共三个, 分别是: 根部真菌-植物互 作、AM真菌-植物互作以及ECM真菌-植物互作矩 阵。为了降低互作矩阵的复杂性, 将序列数所占比 例低于 $0.01 \%$ 的序列对应的OTUs剔除。分别从群落 和功能群两个不同的层次分析真菌-植物互作网络 的结构特性。群落水平的网络特性指数有嵌套、专 一性及平均每物种连接性; 功能群水平的指数有生 态位重叠、伙伴多样性、C-score等，分别对植物和 真菌进行计算。

网络的嵌套性用两个指数来度量：一个是 NODF (nestedness metric based on overlap and decreasing fill), 它是基于网络的填充度与成对物种之间 伙伴重叠度的嵌套性; 另一个是考虑了物种之间相 互作用强弱的加权NODF (weighted NODF, WNODF) (Almeida-Neto \& Ulrich, 2011)。采用Patefield's零模 型检验真菌-植物互作网络的嵌套性是否显著高于 (嵌套)或低于(反嵌套)零模型预测值, 该零模型假 定物种间随机互作，同时又保持互作矩阵的行与列 和实际观察到的互作矩阵相同(Patefield, 1981)。

连接性(connectance) 是指观察到的相互作用数 占总的潜在相互作用数的比例, 是描述网络整体水 平专一性的指数, 连接性越高表明网络本身的专一 性越低。

专一性是指物种会选择性或偏好性地与潜在 的伙伴共生, 它是一个基于生态位的指数。网络水 平专一性程度用 $H_{2}^{\prime}$ 来表示, 取值介于 $0-1$ 之间, 越 大专一性越高。该指数侧重于度量生态位分化程 度。组群水平的专一性用 $\mathrm{e}^{\mathrm{H}}$ 表示, $\mathrm{e}$ 为自然对数底数, $H$ 为某物种的共生伙伴的Shannon多样性指数, 再 用行/列之和加权。植物的伙伴多样性称generality, 而真菌的伙伴多样性称vulnerability, 该指数侧重于 
展示生态位的宽度。

Checkboard score (C-score) 用于指示两个或两 个以上的物种在一系列的生境中分布的随机性。 C-score极低时, 意味着物种在分布上具有高度随机 性，即一个物种的分布不受其他物种分布的影响。 C-score也是种间竞争程度的一个指针, 高C-score 对应高强度种间竞争。

所有数据分析在R v3.5.1 (https://www.R-project. org/)中进行，使用的软件包有vegan v2.5.2、igraph v1.0.1、ggplot2 v3.1.0、 bipartite v2.11。

\section{2 结果}

\section{1 热带山地雨林根部真菌群落的谱系多样性}

对热带山地雨林混生的槭树科、番荔枝科、夹 竹桃科、冬青科、棕㭣科、壳斗科、樟科和木犀科 等8科植物的RAF的ITS1区进行高通量测序, 共获 得真菌序列达 297,831 reads。媒 $200 \mathrm{bp}$ 以上的序列 占75\%以上, 主要集中于 $200-320 \mathrm{bp}$ 间, 每科植物 的真菌reads数介于31,589-50,791。稀释(rarefied)曲 线显示, 当每科植物根系样品的测序深度达到 20,000 reads以上时, 真菌物种数增加的趋势变平 缓(图1)。因此, 本研究的样品测序深度能够较为全 面地反映热带山地雨林常见植物RAF多样性。

将每科植物的 RAF稀释后达 31,588或 31,589 reads, 8 科植物的RAF合计达 252,710 reads, 包含 1,279 个OTUs。尖峰岭热带山地雨林中, 槭树科植 物的真菌OTUs数最多(701), 壳斗科最少(359)。在 1,279 个真菌OTUs中, reads占总数 $0.01 \%$ 以上的真菌 有 420 种, 对应 $96.8 \%$ 的reads, 被称为核心 RAF群 落。相比之下, 余下 $76 \%$ 的真菌OTUs仅占总 reads 的 $3.2 \%$ 。核心RAF群落中, 真菌的OTUs数介于 217
(壳斗科)至334 (冬青科)之间。RAF群落物种多样性 最高的为冬青科与樟科, 其Shannon多样性指数分 别为 4.05 和 4.04 , 最低的是壳斗科和夹竹桃科, 均 为2.58 (表1)。

核心RAF群落中，有406个(96.6\%) OTUs鉴定 到门, 350 个(83.3\%)鉴定到目, 242 个(57.6\%)鉴定到 科, 142 个(33.8\%)鉴定到属。在门级分类单元，核心 RAF群落中物种最多的是子囊菌门, 在 8 科植物中 平均为 $160 \pm 9$ (平均值士标准误)种。子囊菌门真菌 在冬青科中物种最丰富，达194种，占该科全部物 种(334种)的 $58.0 \%$, 其序列数 $(22,312$ 条)占该科真菌 序列总数(29,934条)的 $74.5 \%$; 在壳斗科植物中, 子 囊菌门真菌有115种，占该科全部物种(217种)的 $52 \%$, 然而其序列数 $(3,681$ 条)仅占该科序列总数 $(30,983$ 条 $)$ 的 $11.8 \%$ 。其次为担子菌门，平均为 $75 \pm 4$ 种真菌。壳斗科中担子菌门真菌有82种, 占该科全 部物种的 $37.7 \%$, 但其序列数 $(27,206$ 条)占该科的 $87.8 \%$ 。相比之下，夹竹桃科植物中担子菌物种数虽 然也比较多(73种), 占该科物种数(277种)的 $26.3 \%$,

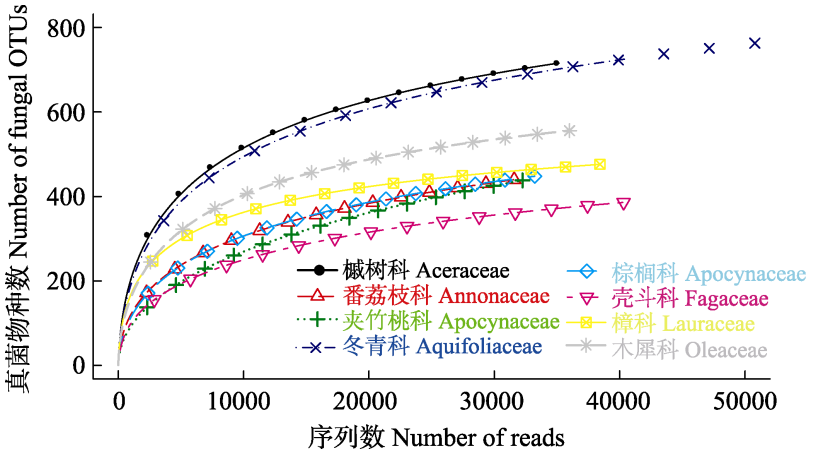

图1 尖峰岭热带山地雨林8科植物根部真菌物种累积曲线

Fig. 1 Rarefaction curves of root-associated fungi of eight plant families in the tropical montane rain forest of Jianfengling

表1 尖峰岭热带山地雨林8科植物的根部真菌群落物种丰富度和多样性

Table 1 Species diversity and richness of root-associated fungal community of eight plant families in the tropical montane rain forest of Jianfengling

\begin{tabular}{lllll}
\hline $\begin{array}{l}\text { 宿主植物 } \\
\text { Host plant }\end{array}$ & $\begin{array}{l}\text { 根样品数 } \\
\text { No. of root samples }\end{array}$ & $\begin{array}{l}\text { 真菌物种数 / reads } \\
\text { No. of fungal species/reads }\end{array}$ & $\begin{array}{l}\text { 核心真菌物种数 / reads } \\
\text { No. of core fungal species/reads }\end{array}$ & $\begin{array}{l}\text { Shannon多样性指数 } \\
\text { Shannon diversity index }\end{array}$ \\
\hline 槭树科 Aceraceae & 34 & $701 / 31,589$ & $328 / 29,817$ & 3.97 \\
番荔枝科 Annonaceae & 32 & $440 / 31,588$ & $256 / 30,846$ & 2.88 \\
夹竹桃科 Apocynaceae & 41 & $434 / 31,589$ & $277 / 31,134$ & $334 / 29,932$ \\
冬青科 Aquifoliaceae & 39 & $675 / 31,588$ & $264 / 30,894$ & 3.05 \\
棕㭣科 Arecaceae & 21 & $436 / 31,589$ & $217 / 30,983$ & 2.58 \\
壳斗科 Fagaceae & 31 & $359 / 31,589$ & $261 / 30,508$ & 3.04 \\
樟科 Lauraceae & 35 & $463 / 31,589$ & $302 / 30,527$ & 3.72 \\
木犀科 Oleaceae & 34 & $546 / 31,589$ & & \\
\hline
\end{tabular}


但是其序列数(841条)仅占该科总序列数 (31,134条) 的 $2.7 \%$ 。球囊菌亚门真菌的物种丰富度在夹竹桃科 (35种)和番荔枝科(37种)植物中较高，分别占 $10.6 \%$ 和 $14.4 \%$, 序列数更是高达 $65.1 \%(20,272$ 条) 和 $57.6 \%$ (17,768条)。球囊菌亚门的真菌物种丰富度在 壳斗科植物中最低, 为 13 种 (占 $6 \%$ ), 其序列所占比 例更低，仅占总序列数的 $0.2 \%$ (76条)。

在目级分类单元, 山地雨林 8 科常见植物的核 心RAF群落的谱系组成有明显差异, 如以球囊需目 为代表的植物有番荔枝科(34种，占总序列数 $57 \%$ ) 和夹竹桃科(31种/61.7\%); 以红菇目为代表的植物 有壳斗科(25种/72.1\%); 以柔膜菌目为代表的植物 有棫树科(55种/26\%)、冬青科(56种/42.9\%)、棕榈科 (50种/19.8\%)、樟科(47种/22.4\%)以及木犀科(56种/ 46.6\%)(图2)。

\section{2 热带山地雨林核心根部真菌群落的功能多} 样性

根据FUNGuild软件分析的结果，在核心 RAF 群落的420种真菌中, 共生型真菌最多(105种), 包 括ECM真菌48种、AM真菌40种、杜鹃花菌根真菌 12 种、内生真菌1种, 还有 4 种与多类宿主(ECM植 物、兰科植物)形成菌根共生关系。这些共生型真菌 的序列数占核心RAF总序列数的 $40.7 \%$ (图3)。ECM 真菌在壳斗科的RAF群落中最多, 占该科总序列数 的79.5\% (图3), 代表性真菌如乳菇(Lactarius sp.1)、 贝弗菌属(Rossbeevera sp.)和红菇属(Russula sp.1) (附录1)。相比之下, AM真菌在夹竹桃科和番荔枝科 的RAF群落中最多, 序列数分别占各自对应的核心 RAF总序列数的 $65.1 \%$ 和 $57.6 \%$; 其次为木犀科、樟 科和槭树科，序列数分别占 $20.1 \%$ 、 $19.7 \%$ 和 $11.2 \%$ (图3), 最常见的 AM真菌为球囊霉 (Glomeraceae sp.1)和(Glomeraceae sp.2) (附录1)。

除共生型真菌外, 山地雨林核心RAF群落中被 确定为腐生型的真菌达 83 种, 其序列数占核心 RAF 总序列数的 $19.8 \%$, 包括植物腐生-木本腐生、土壤腐 生、未知腐生真菌等。其中植物腐生-木本植物腐 生型真菌在各科宿主的核心 RAF群落中约占总序 列数的 $20 \pm 2 \%$ 。腐生型真菌在木犀科中最多, 序列 数占 $26.7 \%$, 在壳斗科中最少, 序列数占 $1.1 \%$ (图3)。 常见的腐生型真菌有晶杯菌Hyaloscyphaceae sp.1、 Hyaloscyphaceae sp.2 和葡萄穗霉 Stachybotryaceae sp.1 (附录1)。此外, 山地雨林RAF群落中少数真菌
(8种)是已知的病原型真菌, 其对应序列仅占核心 RAF群落总序列数的 $0.7 \%$ (图3)。代表性真菌有柱霉 (Scytalidium sp.1)、丽赤壳菌(Calonectria sp.)和何德 毛结节菌(Piedraia hortae) (附录1)。核心RAF群落中 尚有 225 种(占总序列数 $38.7 \%$ )真菌具有两种以上的 营养型或尚不能根据分类信息推断其生态类型(图3)。

\section{3 根部真菌-植物互作网络结构特征}

用于网络特征分析的 3 个互作矩阵为: 根部真 菌-植物(真菌420 × 植物8)、AM真菌-植物(真菌40 $\times$ 植物 8$) 、$ ECM真菌-植物(真菌 $48 \times$ 植物 8$)$ 。网络 的嵌套值在 $A M$ 互作网络中最高 $(\mathrm{NODF}=68.39)$, 显著高于零模型预测值 $\left(\mathrm{NODF}_{\text {null }}=60.70, P=0.025\right)$; 在ECM互作网络中最低 $(\mathrm{NODF}=26.06)$, 显著低于 零模型预测值 $\left(\mathrm{NODF}_{\text {null }}=58.36, P=0.000\right)$; 而根 部真菌-植物互作网络的嵌套值介于二者之间 $(\mathrm{NODF}=32.59)$, 显著高于零模型预测值 $\left(\mathrm{NODF}_{\text {null }}\right.$ $=9.40, P=0.000)$ (表2, 图4)。对于加权的嵌套性指 数WNODF (weighted NODF), 除了AM互作网络外, 其他两类网络表现出与NODF相似的特征。

在专一性方面, ECM互作网络的专一性最高 $\left(H_{2}^{\prime}=0.81\right)$, 其次是根部真菌-植物互作网络 $\left(H_{2}^{\prime}=\right.$ $0.54)$, 而 $\mathrm{AM}$ 互作网络最低 $\left(H_{2}^{\prime}=0.31\right)$, 三者的专一 性都显著高于各自对应的零模型预测值 $(P<0.005)$ 。 网络的连接性在AM互作网络中最高 $\left(\right.$ Connectance ${ }_{\mathrm{am}}=$ 0.42), 而在ECM互作网络与根部真菌-植物互作网 络中相近, 分别为 0.21 和 0.26 , 三者均显著低于物 种间随机互作的网络 $(0.87-0.99, P=0.000)$ 。

从植物或真菌功能群水平看, 在生态位分化方 面, 三个网络中, 植物的共生真菌生态位重叠均显 著低于零模型预测值 $(P<0.001)$ 。在AM互作网络及 根部真菌-植物互作网络中，植物的共生菌生态位 重叠度 (niche overlapamf $=0.46$, niche overlap raf $=$ 0.25) 高于真菌的宿主植物生态位重叠度 (niche overlap $_{a m p}=0.35$, niche overlap rafp $=0.19$ ); 而ECM互 作网络表现出相反的趋势, 即植物的共生伙伴生态 位重叠度(niche overlapemp $=0.11$ )低于真菌的共生 伙伴生态位重叠度 (Niche overlapemf $=0.39$ )。加权后 的植物的伙伴多样性(generality) 在3个网络中均高 于真菌的伙伴多样性(vulnerability), 并且均低于零 模型预测值。虽然AM互作网络与ECM互作网络中, 植物和真菌的伙伴多样性较接近(5.46 vs. 5.32); 但 是在伙伴多样性方面, ECM真菌明显低于AM真菌 
(1.28 vs. 3.41)。植物的种间共现C-score值在AM互 作网络和ECM互作网络中均与零模型预测值无显 著差异, 而在根部真菌-植物互作网络中(C-score = $0.38)$ 显著低于零模型预测值 $\left(\mathrm{C}-\mathrm{score}_{\text {null }}=0.96, P=\right.$ 0.000)。真菌的种间共现频度在AM互作网络中
$(\mathrm{C}$-score $=0.24)$ 显著高于零模型 $(\mathrm{C}$-score null $=0.02$, $P=0.000)$, 在根部真菌-植物互作网络中 $(\mathrm{C}$-score $=$ $0.62)$ 显著低于零模型 $\left(\mathrm{C}-\right.$ score $\left._{\text {null }}=0.85, P=0.000\right)$, 而在ECM互作网络中 $(\mathrm{C}$-score $=0.52)$ 与零模型预测 值无显著差异 $\left(\mathrm{C}-\right.$ score $\left._{\text {null }}=0.43, P=0.153\right)$ (表2)。

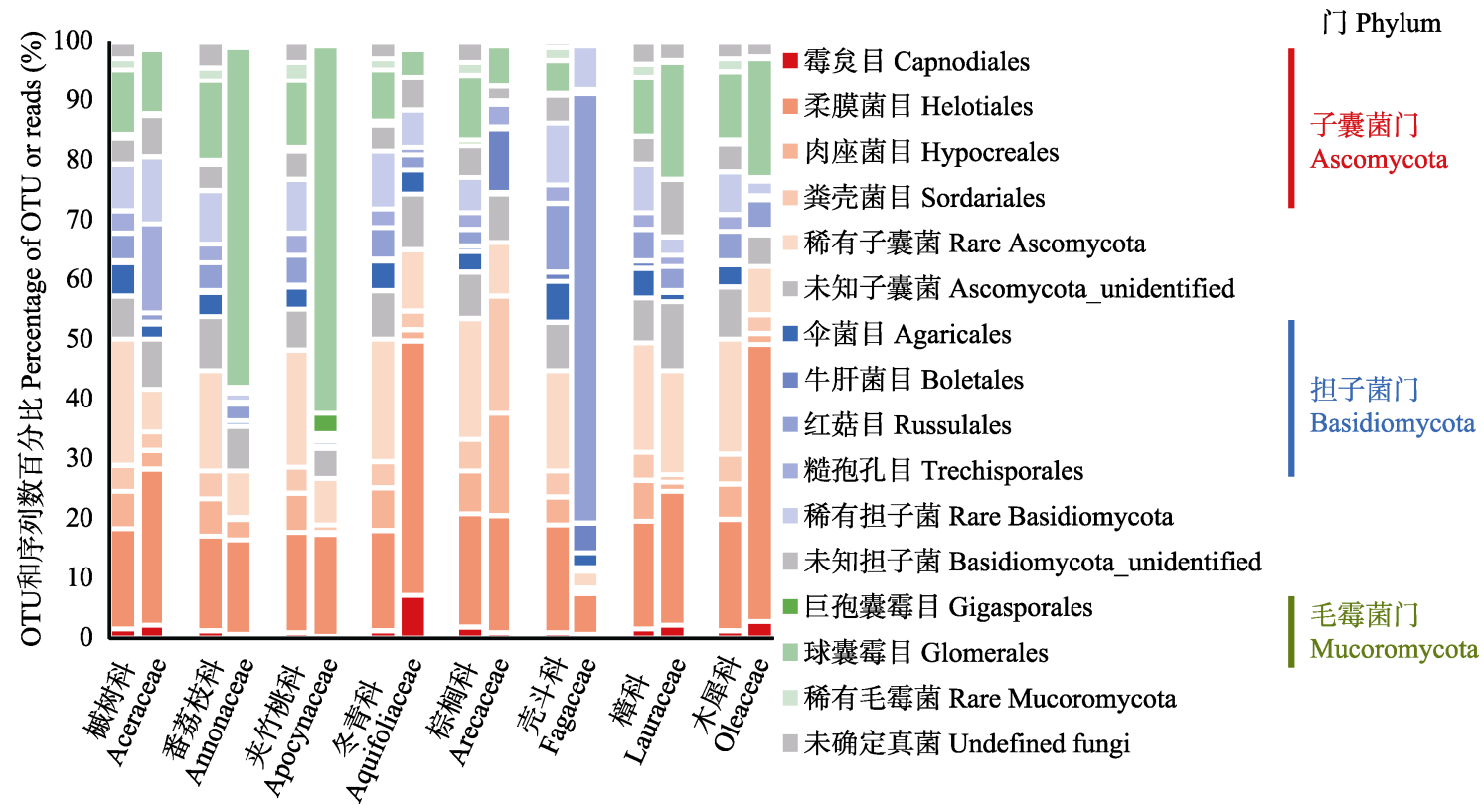

图2 尖峰岭热带山地雨林8科植物的根部真菌目组成差异。每科植物对应的左柱与右柱分别为OTUs和reads百分比。

Fig. 2 Compositional differences of root-associated fungi by order among the eight plant families in the tropical montane rain forest of Jianfengling. For each plant family, left and right column are percentage of OTUs and reads, respectively.

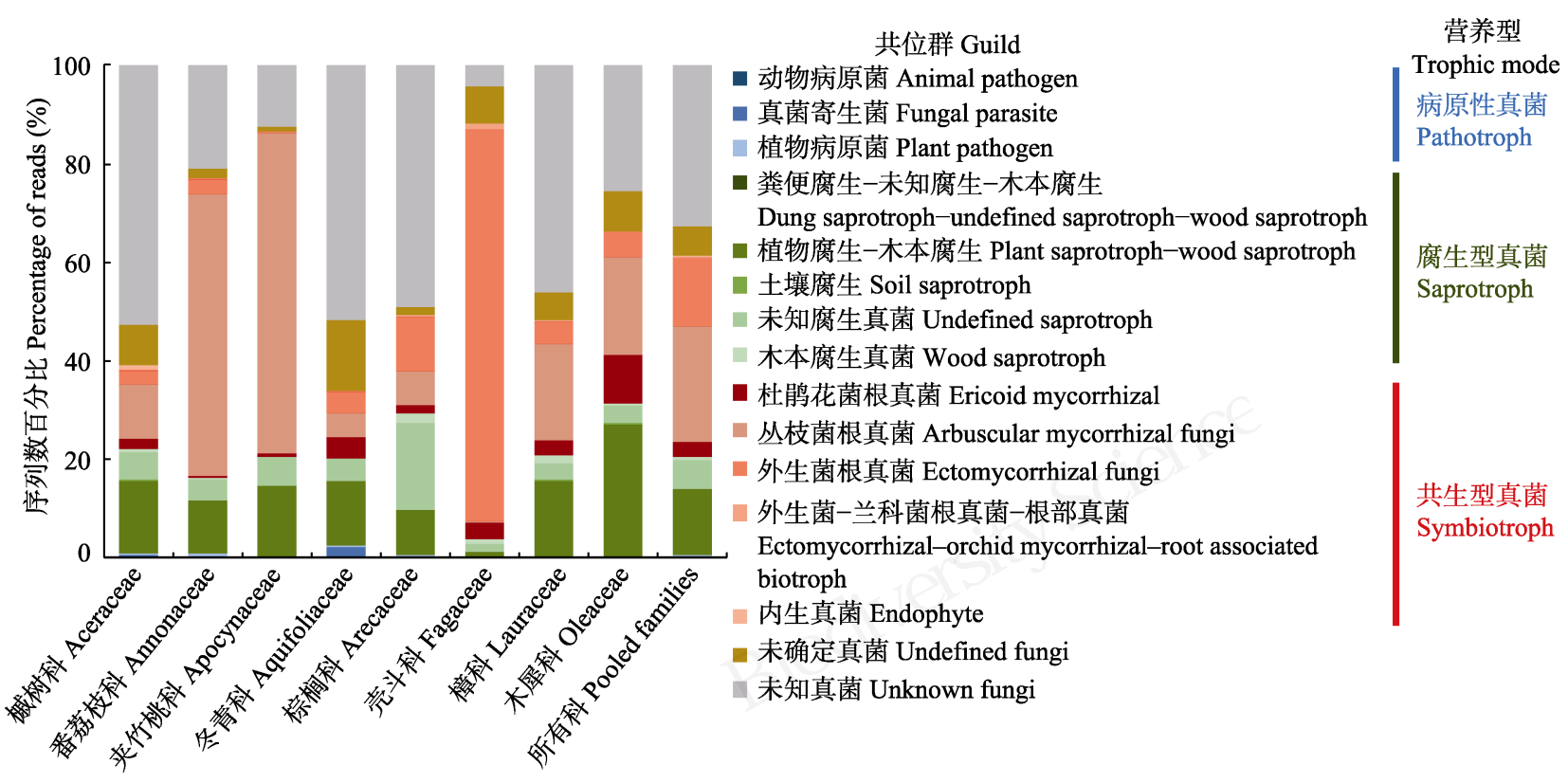

图3 尖峰岭热带山地雨林8科植物的根部不同共位群和营养型真菌的序列百分比组成差异

Fig. 3 Compositional differences in reads of root-associated fungi by guilds and trophic modes of the eight plant families in the tropical montane rain forest of Jianfengling 
表2 根部真菌-植物互作网络结构特性指数

Table 2 Structural features of root-associated fungus-plant interaction networks

\begin{tabular}{|c|c|c|c|c|c|c|}
\hline & \multicolumn{2}{|c|}{$\begin{array}{l}\text { 丛枝菌根网络 } \\
\text { Arbuscular mycorrhizal network }\end{array}$} & \multicolumn{2}{|c|}{$\begin{array}{l}\text { 外生菌根网络 } \\
\text { Ectomycorrhizal network }\end{array}$} & \multicolumn{2}{|c|}{$\begin{array}{l}\text { 根部真菌-植物互作网络 } \\
\text { Root-associated fungus-plant } \\
\text { network }\end{array}$} \\
\hline & $\begin{array}{l}\text { 观察值 } \\
\text { Observed }\end{array}$ & $\begin{array}{l}\text { 零模型 } \\
\text { Null model }\end{array}$ & $\begin{array}{l}\text { 观察值 } \\
\text { Observed }\end{array}$ & $\begin{array}{l}\text { 零模型 } \\
\text { Null model }\end{array}$ & $\begin{array}{l}\text { 观察值 } \\
\text { Observed }\end{array}$ & $\begin{array}{l}\text { 零模型 } \\
\text { Null model }\end{array}$ \\
\hline $\begin{array}{l}\text { 网络嵌套性 } \\
\text { Nestedness metric based on overlap and } \\
\text { decreasing fill, NODF }\end{array}$ & 68.39 & 60.70 & 26.06 & 58.36 & 32.59 & 9.40 \\
\hline 网络加权嵌套性 Weighted NODF & 45.12 & 53.76 & 18.04 & 48.44 & 20.46 & 7.69 \\
\hline 网络专一性 Specialization $\left(H_{2}^{\prime}\right)$ & 0.31 & 0.01 & 0.81 & 0.01 & 0.54 & 0.01 \\
\hline 网络连接性 Connectance & 0.42 & 0.88 & 0.21 & 0.89 & 0.26 & 0.99 \\
\hline 植物生态位重叠 Niche overlap of plants & 0.46 & 0.99 & 0.11 & 0.99 & 0.25 & 0.99 \\
\hline 真菌生态位重叠 Niche overlap of fungi & 0.35 & 0.97 & 0.39 & 0.98 & 0.19 & 0.91 \\
\hline 植物的伙伴多样性 Generality of plants & 5.46 & 7.87 & 5.32 & 10.92 & 34.14 & 87.31 \\
\hline 真菌的伙伴多样性 Vulnerability of fungi & 3.41 & 4.84 & 1.28 & 2.74 & 3.16 & 7.95 \\
\hline 植物Checkboard值 C-score of plants & 0.17 & 0.28 & 0.62 & 0.48 & 0.38 & 0.96 \\
\hline 真菌Checkboard值 C-score of fungi & 0.24 & 0.02 & 0.52 & 0.43 & 0.62 & 0.85 \\
\hline
\end{tabular}

Patefield's零模型(Patefild's null model)算法随机分配真菌与植物的互作次数(Patefield, 1981), 同时确保每种真菌、植物的相互作用总次数与真 实网络相同。数字加粗表示网络指数观察值显著高于/低于零模型预测值。

Patefield's null model algorithm randomly distribute interactions to matrix with the number of interactions per plant and fungal species the same as in the real interaction matrix (Patefield, 1981). Numbers in bold indicate the values of network indices are significantly higher/lower than that of the values predicted by null models.

\section{3 讨论}

跨界生物的种间互作是影响群落构建的重要 因素(Bascompte et al, 2003; Thebault \& Fontaine, 2010)。RAF是生态系统的重要功能性真菌(Toju et al, 2013a; Almario et al, 2017), 研究热带森林的植物与 RAF的种间互作特性, 有助于揭示热带森林多样性 维持机制。

\section{1 热带山地雨林植物根部真菌谱系与功能多样性}

准确、快速、全面地鉴定RAF及宿主植物是研 究二者的种间互作特性的前提。本研究采用Illumina Miseq高通量测序平台检测了海南尖峰岭热带山地 雨林的械树科、番荔枝科、夹竹桃科、冬青科、棕 榈科、壳斗科、樟科和木犀科等 8 科常见植物的 $\mathrm{RAF}$ 。结果表明, 海南岛的热带山地雨林RAF群落 除了意料中的高度多样性以外, 多种生态功能的真 菌共存于同科近缘宿主植物根部的现象极普遍。在 山地雨林的 420 种核心真菌中, 近一半(46.4\%)生态 类型较明确。在已知生态型的真菌中, 共生型真菌 最常见，占 $47.7 \%$ (ECM和AM各占 $24.6 \%$ 和 $20.5 \%$ ), 其次是腐生型真菌 (42.5\%)及少量的病原型真菌 (4.1\%)。世界上热带地区报道最广泛的RAF是AM真
菌, 通常认为ECM共生关系在热带地区较少或缺 失。近期的研究表明, 虽然大多数的热带森林被AM 植物主导, 却也不乏ECM植物种(Corrales et al, 2018)。与世界上其他热带地区不同，东南亚地区的 热带森林中, 已确定能形成外生菌根的植物绝大多 数是山龙眼科植物(占已知ECM植物物种数的 $83 \%$ ), 而最典型的ECM宿主壳斗科植物仅有少量报道(占 5.1\%) (Corrales et al, 2018)。海南岛地处东南亚地区 热带北缘, 尖峰岭山地雨林具有由热带雨林向亚热 带/暖温带雨林过渡的性质，如在一个 1 ha的样方中， 壳斗科竟达3属23种(方精云等, 2004)。正是由于尖 峰岭热带山地雨林ECM壳斗科植物种类与数量多, 其RAF群落中ECM真菌多样性也相应较高。据此, 在研究东南亚的热带地区ECM真菌多样性时, 需要 考虑热带北缘山地生态系统，才能较为全面地反映 本地区的ECM真菌和宿主植物的多样性。

相对于ECM宿主植物而言, 尖峰岭热带山地 雨林中绝大多数物种为 $\mathrm{AM}$ 植物, 因此, 其 $\mathrm{RAF}$ 群 落中AM真菌极常见, 最常见的球囊需(Glomeraceae sp.)和根内球囊霉(Rhizophagus intraradices)在多类 植物上检测到，这类真菌被认为通过产生丛枝或根 外菌丝体来帮助植物吸收营养(Toju et al, 2013a)。尤 

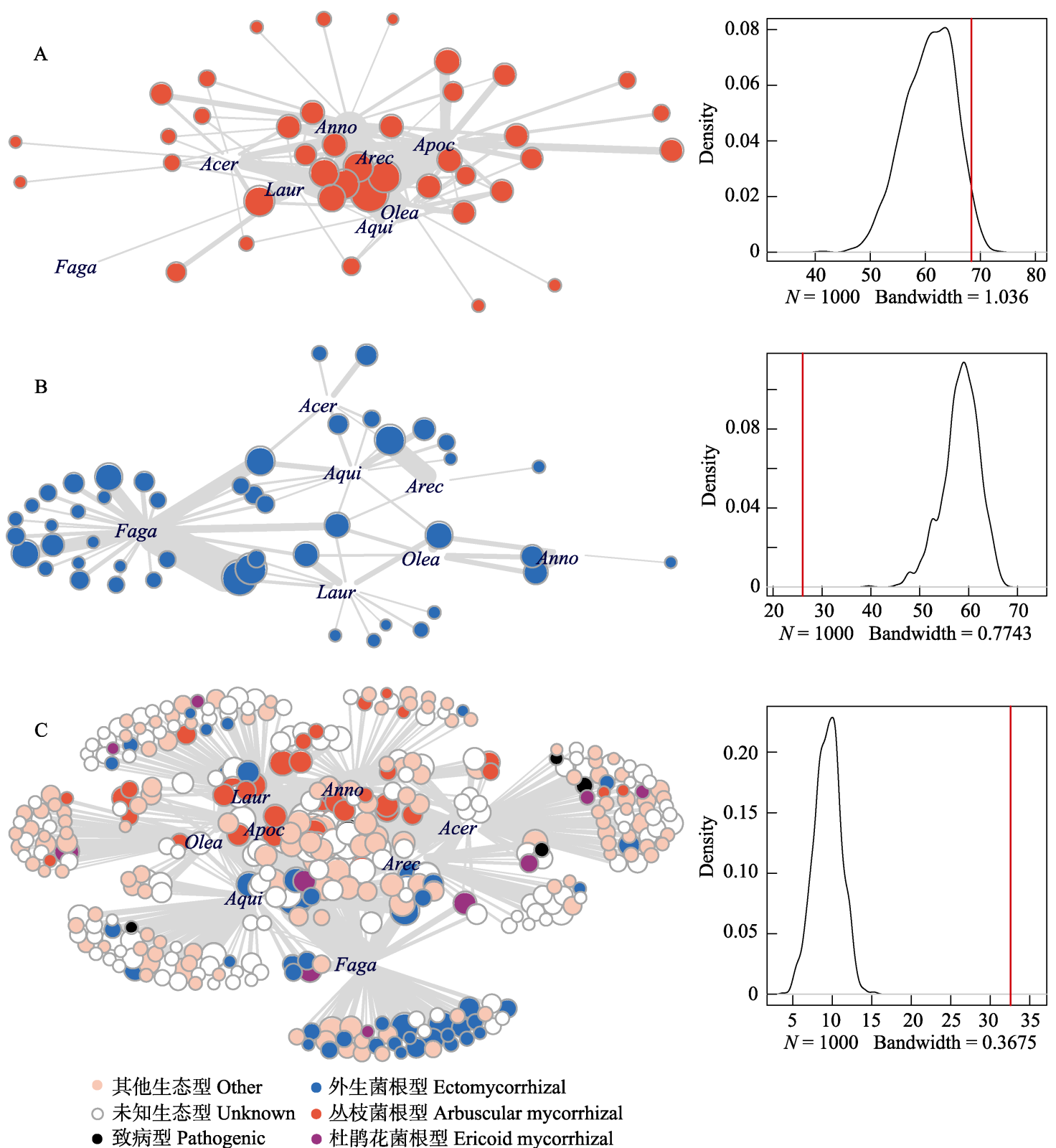

图4 尖峰岭热带山地雨林根部真菌与植物的种间相互作用网络结构(左)与嵌套性(NODF)密度函数图及嵌套性实际观察值 (红色垂直线)(右)。(A)丛枝菌根互作网络; (B)外生菌根互作网络; (C)所有根部真菌-植物互作网络。Acer: 槭树科; Anno: 番 荔枝科; Apoc: 夹竹桃科; Aqui: 冬青科; Arec: 棕桐科; Faga: 壳斗科; 灰色连线代表真菌与宿主的种间互作, 线宽对应互作 强弱。

Fig. 4 Root-associated fungus-plant interaction networks (left) with density plots showing the distribution of nestedness (NODF) predicted by Patefiled's null model (right) and observed nestedness (red vertical line) in tropical montane rain forest of Jianfenling Mountain Hainan Island. (A) and (B) are partial networks of AM and ECM interactions, and (C) is the whole root-associated fungus-plant interaction network. Acer, Aceraceae; Anno, Annoaceae; Apoc, Apocynaceae; Aqui, Aquifoliaceae; Arec, Arecaceae; Faga, Fagaceae; Laur, Lauraceae; Olea, Oleaceae. Interactions between plant and fungi are indicated by grey lines with thickness proportional to interaction strength.

其是热带地区的土壤通常缺乏磷元素，AM真菌定 殖于植物根部皮层细胞可以促进植物吸收磷元素 (Cardoso et al, 2017)。此外, 本研究的山地雨林RAF 群落中, 柔膜菌类的小型真菌极常见, 是樟科、冬
青科、棕㭣科、槭树科以及木犀科的RAF群落中最 有代表性的真菌。柔膜菌类的小型真菌常被报道为 腐生型(Cannon \& Kirk, 2007), 近期的一项研究表 明，某种柔膜菌的基因组中包含有两个高亲和性磷 
转运系统, 在土壤极度缺磷的环境中, 这类真菌能 有效地促进非菌根植物高山南芥(Arabis alpine)的 生长以及地上部分P的累积量(Almario et al, 2017)。 据此, 我们推测本研究的山地雨林绝大多数植物应 对环境磷胁迫的策略除了众所周知的AM互作途径 以外(Smith \& Read, 2008; Cardoso et al, 2017), 与 柔膜菌目的小型真菌互作也是一条潜在的重要途 径。因此, 进一步揭示柔膜菌目真菌在热带山地雨 林养分循环中的作用, 必将有助于加深了解RAF在 热带森林物种多样性维持中的作用。

\section{2 不同功能型的根部真菌-植物互作网络结构特 性与热带山地雨林物种共存机制}

自 20 世纪初以来, 研究人员借助网络分析法揭 示了生物的种间互作在群落水平的普遍特性, 如嵌 套性、模块性、专一性等。这些结构特性被认为能 减少种间竞争、增加系统冗余性, 或加强生态位分 化, 从而使生物群落更加稳定 (Bascompte et al, 2003; Bastolla et al, 2009)。我们的结果显示, 尖峰岭 热带山地雨林中, 根部真菌-植物互作网络的嵌套 性、连接性、专一性等指标均显著高于/低于假定物 种随机互作的零模型预测平均值, 说明除了生境过 滤以外(Blaalid et al, 2014; Kivlin et al, 2014), 生物 的种间互作是微生物群落构建的重要机制。更重要 的是, 本研究结果表明, 在同一山地雨林样地内, 不同功能型的根部真菌-植物互作网络表现出不同 甚至相反的结构特性, 如在群落水平, AM互作网络 表现为高嵌套性和高连接性(NODF $=68.39$, Connectance $=0.42)$ 、低专一性 $\left(H_{2}^{\prime}=0.31\right)$; 相比之下, ECM互作网络呈低嵌套性和低连接性 $(\mathrm{NODF}=$ 26.06 , Connectance $=0.21)$ 、高专一性 $\left(H_{2}^{\prime}=0.81\right)$ 。 嵌套性与专一性是生物互作网络的两个互补的结 构特性, 前者侧重度量互作网络的咒余性(Burkle et al, 2013), 后者侧重描述生态位分化(Blüthgen et al, 2008)。互作网络嵌套性越高的生物群落整体上更能 适应环境干扰, 有较高的稳定性和持久性(Bascompte et al, 2003; Burkle et al, 2013)。物种间较高的生 态位分化使其能利用不同资源，可以避免对有限资 源的竞争，从而促进多样的物种共存(Pianka, 1974; Blüthgen et al, 2008)。

在功能群水平, 从植物视角看, 生态位重叠度 在AM互作网络高于ECM互作网络(0.46 vs. 0.11), 说明AM植物种间竞争强度弱, 生态位分化程度低,
而ECM植物种间竞争强，驱动生态位高度分化; 植 物生态位宽度在AM互作网络与ECM互作网络中较 接近(5.46 vs. 5.32), 说明在山地雨林中, ECM植物 与 $\mathrm{AM}$ 植物能利用的真菌资源相当。从真菌视角看, 生态位重叠度在两类互作 (AM 与 ECM) 中较接近 (0.35 vs. 0.39), 生态位宽度在ECM互作网络低于 AM互作网络(1.28 vs. 3.41)。说明AM真菌与ECM真 菌群落内部种间竞争强度相近, 但ECM真菌在利用 宿主植物资源方面的生态位较AM窄，当环境(宿主 植物资源)变化时, ECM真菌比AM真菌脆弱, 因此, 保护热带山地雨林ECM宿主植物多样性对保持 ECM真菌多样性而言较为关键。

物种共现格局是推断有机体之间潜在互作关 系(如竞争或互利)的有效方法(Gotelli \& McCabe, 2002)。本研究的共现网络分析结果显示, 在ECM群 落内, 真菌或植物的种间对资源的竞争强度极高 (C-score: 植物 0.62, 真菌 0.52), 而 AM群落的物种 无明显种间竞争(C-score: 植物 0.17 , 真菌0.24), 这 一结果再次说明高度的种间竞争驱动ECM互作网 络的反嵌套性。本研究发现的根部真菌-植物互作 网络在群落与功能群水平的互作特性均说明, 热带 山地雨林AM互作网络与ECM互作网络分别采用两 种不同的互作机制来维持群落的稳定性, 即 AM种 间互作的嵌套性(咒余性)和ECM种间竞争驱动的高 度生态位分化。

\section{3 生态网络分析法应用于微生物_植物互作网络} 研究中的潜在问题

$\mathrm{RAF}$ 是生态系统的重要功能性真菌, 然而由于 其生活场所甚至及其自身形态的隐蔽性，其与植物 的互作网络结构特性研究滞后于其他生物互作网 络, 如传粉网络、种子传播网络、食物网(Bascompte et al, 2003; Fortuna et al, 2010; Thebault \& Fontaine, 2010; Burkle et al, 2013)。当前, 植物与RAF的互作 网络关系研究大部分是在单一菌根型宿主植物为 建群种的草地、农田生态系统开展(Chagnon et al, 2012; Gao et al, 2019), 温带与亚热带森林的少量研 究只关注单一的菌根型(Bahram et al, 2014; Taudiere et al, 2015; Chen et al, 2017)。近期，高通量测序技术 揭示了植物的根部能同时被不同功能型真菌群侵 染(Toju et al, 2013b)。在本研究的热带山地雨林中, $A M$ 真菌和ECM真菌可共存于RAF群落。因此, 当前 主流的单一功能型真菌-植物互作网络的研究, 极 
可能忽视了不同功能型真菌与植物差异性的种间互 作(Yamamoto et al, 2014)对群落构建的潜在影响。

此外, 物种极度丰富的热带森林地下根系盘根 错节, 本研究借助当前常用植物DNA条形码序列鉴 定根系身份, 从而使抽取到的根系更接近地下根系 群落实际组成。然而, 即使采用高度变异DNA条形 码序列trnH-psbA (Kress et al, 2009), 本研究显示壳 斗科、樟科植物在属以下水平以及少数几个属间缺 少变异。因此, 本研究在植物科级分类单元研究根 部真菌-植物互作网络结构的特性, 有可能掩盖科 以下分类等级的谱系信号(Chen et al, 2017)。

本研究采用高通量测序技术发现海南尖峰岭 热带山地雨林常见植物的RAF群落不仅谱系多样 性高, 而且生态功能类型丰富。与之前绝大多数只 关注单一功能型的根部真菌-植物互作的研究不同, 本研究在同一个地点不仅分析根部真菌-植物互作 完整网络, 还比较不同功能性真菌-植物的互作网 络(如AM互作网络、ECM互作网络)的结构特性。
网络结构多数指标均不能被假定物种随机互作的 零模型预测。在群落水平, 不同功能型的根部真菌植物互作网络表现出不同或相反的结构特性, 如 AM互作网络表现为高嵌套性和高连接性、低专一 性, 而ECM互作网络呈低嵌套性和低连接性、高专 一性。这一结果意味着热带生物群落可能通过至少 两种及以上的种间互作机制调节群落构建。

致谢: 感谢佛罗里达国际大学刘虹教授审阅英文摘 要; 海南大学罗江涛和刘超协助野外采样; 俞瑶、 陶静、赵世方和萧芳菲协助植物与真菌分子检测。

\section{参考文献}

Almario J, Jeena G, Wunder J, Langen G, Zuccaro A, Coupland G, Bucher M (2017) Root-associated fungal microbiota of nonmycorrhizal Arabis alpina and its contribution to plant phosphorus nutrition. Proceedings of the National Academy of Sciences, USA, 114, 9403-9412.

Almeida-Neto M, Ulrich W (2011) A straightforward computational approach for measuring nestedness using quantitative matrices. Environmental Modelling and Software, 26, 173-178.

Bahram M, Peay KG, Tedersoo L (2014) Local-scale biogeography and spatiotemporal variability in communities of mycorrhizal fungi. New Phytologist, 205, 1454-1463.
Bascompte J (2007) Networks in ecology. Basic and Applied Ecology, 8, 485-490.

Bascompte J, Jordano P, Melián CJ, Olesen JM (2003) The nested assembly of plant-animal mutualistic networks. Proceedings of the National Academy of Sciences, USA, 100, 9383-9387.

Bastolla U, Fortuna MA, Pascual-Garcia A, Ferrera A, Luque B, Bascompte J (2009) The architecture of mutualistic networks minimizes competition and increases biodiversity. Nature, 458, 1018-1020.

Blaalid R, Davey ML, Kauserud H, Carlsen T, Halvorsen R, Hoiland K, Eidesen PB (2014) Arctic root-associated fungal community composition reflects environmental filtering. Molecular Ecology, 23, 649-659.

Blüthgen N, Fründ J, Vázquez DP, Menzel F (2008) What do interaction network metrics tell us about specialization and biological traits. Ecology, 89, 3387-3399.

Burkle LA, Marlin JC, Knight TM (2013) Plant-pollinator interactions over 120 years: Loss of species, co-occurrence, and function. Science, 339, 1611-1615.

Cannon PF, Kirk PM (2007) Fungal Families of the World. CABI Bioscience, Wallingford.

Cardoso EJBN, Nogueira MA, Zangaro W (2017) Importance of mycorrhizae in tropical soils. In: Diversity and Benefits of Microorganisms from the Tropics (eds de Azevedo J, Quecine M), Springer, Cham.

Chagnon PL, Bradley RL, Klironomos JN (2012) Using ecological network theory to evaluate the causes and consequences of arbuscular mycorrhizal community structure. New Phytologist, 194, 307-312.

Chen L, Zheng Y, Gao C, Mi XC, Ma KP, Wubet T, Guo LD (2017) Phylogenetic relatedness explains highly interconnected and nested symbiotic networks of woody plants and arbuscular mycorrhizal fungi in a Chinese subtropical forest. Molecular Ecology, 26, 2563-2575.

Corrales A, Henkel TW, Smith ME (2018) Ectomycorrhizal associations in the tropics-Biogeography, diversity patterns and ecosystem roles. New Phytologist, 220, 1076-1091.

Dickie KH, Cann C, Norman EC, Bamforth CW, Muller RE (2001) Foam-negative materials. Journal of the American Society of Brewing Chemists, 59, 17-23.

Edgar RC (2010) Search and clustering orders of magnitude faster than BLAST. Bioinformatics, 26, 2460-2461.

Edgar RC (2013) UPARSE: Highly accurate OTU sequences from microbial amplicon reads. Nature Methods, 10, 996.

Edgar RC (2018) Accuracy of taxonomy prediction for $16 \mathrm{~S}$ rRNA and fungal ITS sequences, PeerJ, 6, e4652.

Fang JY, Li YD, Zhu B, Liu GH, Zhou GY (2004) Community structures and species richness in the montane rain forest of Jianfengling, Hainan Island, China. Biodiversity Science, 12, 29-43. (in Chinese with English abstract) [方精云, 李 意德, 朱彪, 刘国华, 周光益 (2004) 海南岛尖峰岭山地 雨林的群落结构、物种多样性以及在世界雨林中的地位. 
生物多样性, 12, 29-43.]

Fortuna MA, Stouffer DB, Olesen JM, Jordano P, Mouillot D, Krasnov BR, Poulin R, Bascompte J (2010) Nestedness versus modularity in ecological networks: Two sides of the same coin? Journal of Animal Ecology, 79, 811-817.

Gao C, Montoya L, Xu L, Madera M, Hollingsworth J, Purdom E, Hutmacher RB, Dahlberg JA, Coleman-Derr D, Lemaux PG, Taylor JW (2019) Strong succession in arbuscular mycorrhizal fungal communities. The ISME Journal, 13, 214-226.

Gotelli NJ, McCabe DJ (2002) Species co-occurrence: A meta-analysis of J. M. Diamond's assembly rules model. Ecology, 83, 2091-2096.

Huang CW, Liao YH, Ding Q (2017) Two sample pooling strategies revealed different root-associated fungal diversity of Rhododendron species. Acta Microbiologica Sinica, 57, 571-581. (in Chinese with English abstract) [黄彩微, 廖映 辉, 丁琼 (2017) 两种混合样品策略对揭示杜鹃花根部 真菌多样性的影响. 微生物学报, 57, 571-581.]

James A, Pitchford JW, Plank MJ (2012) Disentangling nestedness from models of ecological complexity. Nature, 487, 227-230.

Jiang YX, Lu JP (1991) Tropical Forest Ecosystem of Jianfengling, Hainan Island, China. Science Press, Beijing. (in Chinese) [蒋有绪, 卢俊培 (1991) 中国海南岛尖峰岭热 带林生态系统. 科学出版社, 北京.]

Kivlin SN, Winston GC, Goulden ML, Treseder KK (2014) Environmental filtering affects soil fungal community composition more than dispersal limitation at regional scales. Fungal Ecology, 12, 14-25.

Kõljalg U, Nilsson RH, Abarenkov K, Tedersoo L, Taylor AFS, Bahram M, Bates ST, Bruns TD, Bengtsson-Palme J, Callaghan TM, Douglas B, Drenkhan T, Eberhardt U, Dueñas M, Grebenc T, Griffith GW, Hartmann M, Kirk PM, Kohout P, Larsson E, Lindahl BD, Lücking R, Martín MP, Matheny PB, Nguyen NH, Niskanen T, Oja J, Peay KG, Peintner U, Peterson M, Põldmaa K, Saag L, Saar I, Schüßler A, Scott JA, Senés C, Smith ME, Suija A, Taylor DL, Telleria MT, Weiss M, Larsson K-H (2013) Towards a unified paradigm for sequence-based identification of fungi. Molecular Ecology, 22, 5271-5277.

Kress WJ, Erickson DL, Jones FA, Swenson NG, Perez R, Sanjur O, Bermingham E (2009) Plant DNA barcodes and a community phylogeny of a tropical forest dynamics plot in Panama. Proceedings of the National Academy of Sciences, USA, 106, 18621-18626.

Merges D, Bálint M, Schmitt I, Böhning-Gaese K, Neuschulz EL (2018) Spatial patterns of pathogenic and mutualistic fungi across the elevational range of a host plant. Journal of Ecology, 106, 1545-1557.

Newsham KK (2011) A meta-analysis of plant responses to dark septate root endophytes. New Phytologist, 190, 783-793.

Nguyen NH, Song Z, Bates ST, Branco S, Tedersoo L, Menke
J, Schilling JS, Kennedy PG (2016) FUNGuild: An open annotation tool for parsing fungal community datasets by ecological guild. Fungal Ecology, 20, 241-248.

Patefield WM (1981) Algorithm AS 159: An efficient method of generating random $\mathrm{R} \times \mathrm{C}$ tables with given row and column totals. Journal of the Royal Statistical Society, Series C (Applied Statistics), 30, 91-97.

Pianka ER (1974) Niche overlap and diffuse competition. Proceedings of the National Academy of Sciences, USA, 71, 2141-2145.

Smith DP, Peay KG (2014) Sequence depth, not PCR replication, improves ecological inference from next generation DNA sequencing. PLoS ONE, 9, e90234.

Smith SE, Read DJ (2008) Mycorrhizal Symbiosis, 3rd edn. Academic Press, London.

Taudiere A, Munoz F, Lesne A, Monnet AC, Bellanger JM, Selosse MA, Moreau PA, Richard F (2015) Beyond ectomycorrhizal bipartite networks: Projected networks demonstrate contrasted patterns between early- and late-successional plants in Corsica. Frontiers in Plant Science, 6, 881.

Tedersoo L, Bahram M, Põlme S, Kõljalg U, Yorou NS, Wijesundera R, Ruiz LV, Vasco-Palacios AM, Thu PQ, Suija A, Smith ME, Sharp C, Saluveer E, Saitta A, Rosas M, Riit T, Ratkowsky D, Pritsch K, Põldmaa K, Piepenbring M, Phosri C, Peterson M, Parts K, Pärtel K, Otsing E, Nouhra E, Njouonkou AL, Nilsson RH, Morgado LN, Mayor J, May TW, Majuakim L, Lodge DJ, Lee SS, Larsson KH, Kohout P, Hosaka K, Hiiesalu I, Henkel TW, Harend H, Guo LD, Greslebin A, Grelet G, Geml J, Gates G, Dunstan W, Dunk C, Drenkhan R, Dearnaley J, Kesel AD, Dang T, Chen X, Buegger F, Brearley FQ, Bonito G, Anslan S, Abell S, Abarenkov K (2014) Global diversity and geography of soil fungi. Science, 346, 1078-1088.

Thebault E, Fontaine C (2010) Stability of ecological communities and the architecture of mutualistic and trophic Networks. Science, 329, 853-856.

Thiéry O, Vasar M, Jairus T, Davison J, Roux C, Kivistik PA, Metspalu A, Milani L, Saks Ü, Moora M, Zobel M, Öpik M (2016) Sequence variation in nuclear ribosomal small subunit, internal transcribed spacer and large subunit regions of Rhizophagus irregularis and Gigaspora margarita is high and isolate-dependent. Molecular Ecology, 25, 2816-2832.

Toju H, Sato H, Yamamoto S, Kadowaki K, Tanabe AS, Yazawa S, Nishimura O, Agata K (2013a) How are plant and fungal communities linked to each other in belowground ecosystems? A massively parallel pyrosequencing analysis of the association specificity of root-associated fungi and their host plants. Ecology and Evolution, 3, 3112-3124.

Toju H, Yamamoto S, Sato H, Tanabe AS, Gilbert GS, Kadowaki K (2013b) Community composition of root-associated fungi in a Quercus-dominated temperate forest: "Codominance” of mycorrhizal and root-endophytic fungi. Ecology and Evolution, 3, 1281-1293. 
Tylianakis JM (2009) Warming up food webs. Science, 323, 1300-1301.

Ulrich W, Gotelli NJ (2007) Null model analysis of species nestedness patterns. Ecology, 88, 1824-1831.

Vázquez DP, Chacoff NP, Cagnolo L (2009) Evaluating multiple determinants of the structure of plant-animal mutualistic networks. Ecology, 90, 2039-2046.

Xu H, Li YD, Lin MX, Wu JH, Luo TS, Zhou Z, Chen DX, Yang H, Li GJ, Liu SR (2015) Community characteristics of a 60 ha dynamics plot in the tropical montane rain forest in Jianfengling, Hainan Island. Biodiversity Science, 23, 192-201. (in Chinese with English abstract) [许涵, 李意德,
林明献, 吴建辉, 骆土寿, 周璋, 陈德祥, 杨怀, 李广建, 刘世荣 (2015) 海南尖峰岭热带山地雨林60 ha动态监测 样地群落结构特征. 生物多样性, 23, 192-201.]

Yamamoto S, Sato H, Tanabe AS, Hidaka A, Kadowaki K, Toju H (2014) Spatial segregation and aggregation of ectomycorrhizal and root-endophytic fungi in the seedlings of two Quercus species. PLoS ONE, 9, e96363.

Zhang J, Kobert K, Flouri T, Stamatakis A (2013) PEAR: A fast and accurate Illumina Paired-End reAd mergeR. Bioinformatics, 30, 614-620.

(责任编委：郭良栋 责任编辑：黄祥忠)

\section{附录 Supplementary Material}

\section{附录1 尖峰岭热带山地雨林核心真菌的谱系和生态类型分类}

Appendix 1 Taxonomic affinites and ecological characters of core fungi in the tropical montane rain forest of Jianfengling http://www.biodiversity-science.net/fileup/PDF/2018339-1.xls 